\title{
棉兰市克萨万唐人街建筑形态
}

\section{Tipomorfologi Arsitektur Bangunan Pecinan Di Kesawan Medan}

\author{
Rudiansyah, Julina \\ Fakultas IImu Budaya Universitas Sumatera Utara, Indonesia \\ E-mail: rudiansyah@usu.ac.id; julina@usu.ac.id
}

\begin{abstract}
摘要
当今大多数棉兰市克萨万街仍然保留着荷兰一中国建筑风格或过渡时代的建 筑遗产, 目前保存历史遗产的意识较少。修改建筑遗产的法律还未完善, 也还未 被指定为文化遗产的古建筑。这种情况使人们担心早晚将失去对原始建筑物的追 踪。本文介绍棉兰唐人街建筑的形态特征。研究报告使用各种书籍和期刊进行研 究。使用 Andre Loeckx 和 Markus Zahnd 的区域形态学理论和建筑物类型学。建 筑物的总体状况并未丢失其原始形式。在重新粉刷, 修复损坏的元件和更改范围 内翻新功能的工作。从材料及其布局可以明显看出其形态。来自周围环境的建筑 材料, 例如砖, 瓦屋顶和窗户。建筑物的布局位于市中心的住宅安置区, 地形平 坦建筑形态很适合热带及湿润气候的印度尼西亚。
\end{abstract}

关键词 : 形态学; 建筑; 唐人街; 荷兰-中国; 棉兰克萨万

\begin{abstract}
Abstrak
Permukiman kesawan Medan sebagian besar masih mempertahankan arsitektur bangunan Belanda-China periode peralihan atau arsitektur Transisi, walaupun kesadaran pelestarian peninggalan bernilai sejarah masih minim. Belum ada peraturan batasan perubahan yang boleh dilakukan dan belum ditetapkan sebagai Bangunan Cagar Budaya. Keadaan ini menimbulkan kekhawatiran akan kehilangan jejak bangunan aslinya. Tulisan ini bermaksud untuk menjelaskan karakteristik tipomorfologi arsitektur bangunan pecinan di Kesawan Medan. Metode yang digunakan adalah desk research terhadap laporan hasil penelitian, berbagai sumber buku dan jurnal. Menggunakan teori morfologi kawasan dan tipologi bangunan dari Andre Loeckx dan Markus Zahnd. Kondisi bangunan secara umum belum kehilangan bentuk aslinya. Renovasi dilakukan dalam batas pengecatan ulang, perbaikan elemen yang rusak, dan perubahan fungsi. Tipomorfologi khasnya tampak dari bahan yang digunakan dan tata letaknya. Bahan
\end{abstract}


bangunan dari lingkungan sekitar, seperti bata, keramik atap genting dan jendela. Tata letak bangunan berada di kawasan emplasemen permukiman pusat kota, dengan topografi lahan datar dalam lingkungan iklim tropis basah Indonesia.

Kata kunci : Tipomorfologi; Arsitektur; Pecinan; Belanda-China; Kesawan Medan

\section{一 绪论}

\section{1 引言}

棉兰克萨万地区的建筑结构及形态特征具有其作为殖民地建筑的独特性。除 了可以从旧建筑物（即荷兰时代）显示物理形态之外, 还可以从其建立历史中补 充这些线索。棉兰克萨万地区成立于 19 世纪后期, 确切地说是 1860 年代 （Nurdin，2020 年）。

棉兰克萨万地区的房屋经过了多次翻新, 没有失去其原始形状。目前只保 留原始风格、舒适故居的形式, 尚未进一步的研究。关于这些历史文物的保护 意识仍然较少, 因为有一些建筑从来没翻新过而被遗弃。到目前为止, 未有修 改故居的法规。此外, 该建筑尚未被指定为文化遗产建筑（BCB）, 引起人们对 其原始建筑形态特征变化的担忧。基于这些问题, 本文描写了克萨万地区建筑 的形态特征及研究目的。

住宅的典型形态通常源于荷兰民族文化, 既纯净与当地元素融为一体, 并适 应印度尼西亚的潮湿热带气候。现代殖民地建筑被称为印欧风格。这种建筑风 格融合了印度尼西亚和欧洲的建这种建筑风格融合了印度尼西亚和欧洲的建筑风 格（Handinoto，2010 年）。欧洲建筑元素与当地（印尼传统）元素的混合风格 也被称为 20 世纪初期的印度风格（Sukiman，2000 年）。棉兰克萨万地区的房 屋确是印欧风格。

印欧风格的建筑主要特征是, 大厅通常是对称的。核心建筑（服务）, 例如 厨房, 女佣的房间, 女佣的浴室（在后面分开）（bijgebouwenen）; 建筑周围 有个大院子; 许多缩小尺寸的门窗; 典型的装饰品; 分层段; 具有门厅的建 筑可减少周围阳光的热量。本文描述当今艾哈迈德 - 亚尼街 (Ahmad Yani) 或俗 称棉兰克萨万地区。 
Indis 风格为印欧风格, 包括现代欧洲建筑, 即以古希腊罗马风格重复出现 在新古典主义建筑。主要在希腊时期使用柱子, 无论是结构还是装饰, 建筑计 划在很大程度上都是对称的。在经历了 19 世纪欧洲（英格兰）的工业革命之 后, 现代欧洲建筑是一个新的建筑概念（Sumalyo，2003 年）。适应当地环境的 现代欧洲建筑似乎作为建筑物的元素, 材料以及建筑物的样式/形状中显示出本 地的建筑元素。从克萨万地区的房屋中可以看到部分现代欧洲建筑的全景。

克萨万地区的房屋估计建于 1860 年代至 1995 年代之间。根据塞缪尔 - 哈 托诺和汉迪诺托（Handinoto \&Hartono，2006 年）的说法, 荷兰东印群岛殖民时 期建筑发展的周期为（1）18 和 19 世纪被归为 Indische 帝国风格; (2) 19 世 纪末-20 世纪初（1890-1915 年）是过渡性的建筑风格; （3）1915 年后的 20 世 纪初-荷兰东印群岛殖民时定为印欧风格或现代殖民地或新东印建筑。

过渡时期通常逃脱了建筑历史学家的视野, 通常被归类为现代殖民时期建 筑。通常, 此过渡架构的平面图几乎与印第帝国架构相似。前廊（voor galerij) 和后廊（achter galerij）和主房间（中央房间）等功能仍然主导着 过渡性的建筑计划。在大型房屋中, 也有通常称为凉亭的侧楼。变革的精神在 于建筑物的外观。在这种过渡性建筑中, voor galerij 或 achter 画廊没有希腊 或罗马风格的柱子（北欧，离子，哥林多风格），这些柱子都代表着印第帝国风 格。

从建筑结构的典型、类型可以看出克萨万地区住宅的独特性。从概念上 讲, 类型学是一种根据基本形式的特征相似性来描述对象组的概念（Loekito, 1994 年; Moneo, 1978 年）。类型学是对与类型相关的所有事物的研究。类 型学一词来自希腊语, 即 typos 类型, logos 为意念, 标志意为表达或思想 （Rudiansyah，2016 年）。

建筑类型学表示在建筑领域中使用元素的类型。类型学用于理解基本概念 或属性, 以便识别现象的异同。类型学是由于一个组合中发生重复而形成的分 组。这些类型特征在建筑物的基本形状中具有相似的特征。克萨万地区的住宅 基本建筑计划的形式上具有相似之处，该建筑计划是正方形的。也有相同的基 本材料和建筑元素，例如抹灰和屋面屋顶材料。同样，屋顶覆盖材料由瓷砖制 
成, 张亚飞故居也使用此材料。

根据罗克 (Loeckx, 1985 年) 的研究, 形态学研究是连接, 相互关系, 位 置, 尺寸, 功能和调节不同类型的结构 (例如组织网络) 的调节类型之间的结构 联系。形态学是一种揭示物理和空间结构的方法, 是形态学和类型学研究的结 合。形态学研究是多种科学因素, 会影响定居的形式。然后, 根据马库斯 - 扎恩 德 (Markus Zahnd) 的观点, 通过映射建筑物类型来读取居住区的形态有八个方 面, 分别如下。（1）建筑平面图：建筑物分为建筑体和开放空间两部分;

(2) Nolli 计划：建筑物分为两部分, 分别是私人/半私人建筑物和开放空间以 及公共/半公共用途建筑物; （三）建筑层数：建筑层数; （4）建筑条件：良 好, 中等, 不良; (5) 建筑面积: 社会地位和计划表; (6) 休息用地和树木 位置; (7) 流通系统: 道路等级可以由汽车, 摩托车, 自行车, 行人穿越;

（8）建筑功能：具有变化功能的住宅或建筑物（Santoni，2014 年）。

克萨万地区住宅建筑的形态特征受地貌条件和农业/人工林地貌的影响。地 貌和地理与影响人类行为和行动的地球表面形状, 土地形式或景观有关。 Bintarto 透露, 从空间或地球表面的角度来看, 人类与其自然环境之间存在相互 关系。克萨万地区位于北苏门答腊棉兰市艾哈迈德 - 亚尼街（Ahmad Yani）。北 苏门答腊岛通常具有复杂的结构和岩石, 并经历了几次构造过程, 因为它是欧洲 板块和澳大利亚板块的交汇处, 裂缝和褶皱导致形成了一系列伴随火山活动的通 道。北苏门答腊的地区之一, 即 Deli Serdang Regency, 具有各种地形和气候地 形, 其中大部分位于北苏门答腊岛东海岸, 通常位于海拔 0-1000 米的地方 （Lobeck，1939 年）。

\section{2 研究方法}

本研究中使用各种书籍和期刊进行研究, 。使用 Andre Loeckx 和 Markus Zahnd 的区域形态学和建筑物类型学理论, 其中通过观察 (以了解当前建筑物的 外观) 收集主要数据, 并通过历时和同步方法收集 (以了解旧建筑物的外观) 数 据。但是在后来的数据分析中, 在辅助数据中, 同步方法只是对历时方法的补 充（Saussure, 1974 年)。研究地点在棉兰艾哈迈德 - 亚尼街各个走廊。研究 的对象是面向街道的整个建筑。 


\section{Jurnal Cakrawala Mandarin \\ Asosiasi Program Studi Mandarin Indonesia}

Vol.5, No.2, Oktober 2021: P111-122 E-ISSN: 2579-4906

在收集主要数据时，直接通过勘测地点，正面及详细记录当前建筑物的整个 立面并记录所有照片或权威的信息来进行调研。同时, 通过网络搜索资料、个 人文档、文章、报纸、从苏门答腊文物局（BWS）、市区法规（PERDA）、市长法 规（PERWAL）搜索照片、图像、研究区域的旧地图及建筑物外墙相关信息或类似 资料。

本研究采用文献进行研究, 涉及主要数据源, 即研究报告和殖民地（荷兰） 档案馆。然后, 对尚未处理和编写的书籍, 期刊文章以及一些现场数据和档案 数据进行文献研究。此外，数据来源是通过采访专家及信息提供者而获得的。

标准样本基于 1860 年代旧建筑的真实性以及克萨万地区的不断建设，工厂大 楼的一场大火曾被烧毁并于 1916 年进行了维修。因此, 估计克萨万地区的所有 建筑物都是在 1860 年代至 1995 年之间建造的（Buiskool，2005 年：73）。

\section{3 研究结果及探讨}

德理地区（Tanah Deli）或棉兰（Medan）市目前是印尼国内拥有自己独特 地区管理的城市之一。这种特殊性使一个地区与另一个地区区别开来, 这就是一 个地区的身份（Lynch，1981 年：12-13）。一个地区的独特性非常重要，需要加 以保留。镇上很容易发现的部分是街道。是否可以从马路上看到城市的形象（雅 各布斯，莫尔金，1992 年：166）。与此陈述相关的是在保护和塑造一个区域的 身份方面非常重要的事情之一就是建筑物外墙设计的价值（Bentley，1980 年： 10）。遵循现有发展或加强已经拥有的东西, 即以遗产的形式, 形成一个区域的 唯一性。可以增强该地区价值的遗产之一就是其历史建筑。历史区域中的一组建 筑物的视觉外观对于保持历史区域的价值特有意义（Lynch，1972 年：32）。

J. Nienhuyis, Van Der Falk 和 E1liot 先在棉兰市建立了许多与东苏门答 腊的熟食烟草种植时代有关的历史建筑。从种植园获得的巨大利润 1874 年开设 了 22 个种植园, 因此荷兰殖民政府于 1887 年 3 月 1 日将东苏门答腊人驻地的首 都从孟加拉国移至棉兰（Sinar，2001 年）。 正是在那时, 基础设施的发展开始 了, 欧洲建筑开始充斥着棉兰市的面貌, 可以说, 当时棉兰的大部分地区由沼泽 组成，城市交通是通过河流进行的。引入古典艺术建筑装饰风格，其应用中试 图与热带自然环境相结合。 
殖民政府建立及支持设施包括棉兰邮局，该邮局成立于 1879 年，与荷兰协 会Wittie Societeit同年成立。1881 年, 德理 Mij 开设了德理 Spoorweg Maatschappi j 铁路公司, 并于 1886 年开设了电话设施, 到 1900 年已有 213 位客 户。考虑到贸易的发展需要货币的流通，特许银行于 1887 年成立了分行，而乌 拉湾的航运大楼则于 1889 年建成。1 888 年建成了棉兰酒店, 以前被称为食品之 家，当时属于园丁最喜欢居住的地方。该酒店还是棉兰市周边种植园的冰镇啤酒 供应商。第一家医院是于 1888 年成立名为 Eerste School voor Openbare Onderwijs。1898 年为当地之子建立了一家名为 Eereste Inlandsche School der 2e Klasse 的学校（Sinar，2001 年）。

\subsection{1 克萨万地区}

德理地区（Tanah Deli）是一个小村庄， 1823 年有 200 个人口，后来 1860 年代开始被荷兰人改建为棉兰市（Medan）。自从荷兰统治者定居在苏门答腊东 海岸以来，棉兰已发展成为重要的花种植园林交易中心，19 世纪末这些园于开始 在棉兰郊区开设新的种植园。种植园公司需要劳动力来开展业务。因此, 他们 从爪哇和中国招募了工人。为什么选择爪哇和中国？ 因为当地劳动力非常少， 而且当地马来人对种植园林工作没感兴趣。

在荷兰种植园和将华人置于中产阶级的荷兰东印政府的帮助下，在槟城、新 加坡和香港的贸易协会的财政援助下，华人控制了从城市到乡村的商店，并在城 市开设了商店。，利用自行车、布料和缝㧅机等来自欧美的进口商品, 为渔民 和当地农民建立保税担保制度。最初, 棉兰华人所有的商店都在克萨万地区。 Kesawan 来自 “Kesawahan”一词，直奔田野，或者荷兰语发音为“ landelijk” （农村）。他们乘水牛车从拉布汉搬到克萨万是因为路上泥泞如膝。荷兰老板 除了骑马之外, 有些还让荷兰俘虏抬着轿子走陆地, 他们从拉布汉到棉兰需要 5 个小时的时间。

荷兰殖民者, 华裔和原住民在克萨万地区及其周围建造了许多具有典型欧洲 建筑风格的宏伟建筑。克萨万地区的空间布局在其建设之初便成为棉兰市的主要 景点, 并且一直沿用至今。这是熟食烟草园丁的城市杰作。从现代欧洲风格的 
建筑中可以看出克萨万地区的独特性。因此, 棉兰市曾经被称为 “苏门答腊岛 的巴黎”（Buiskool，1999 年：2）。

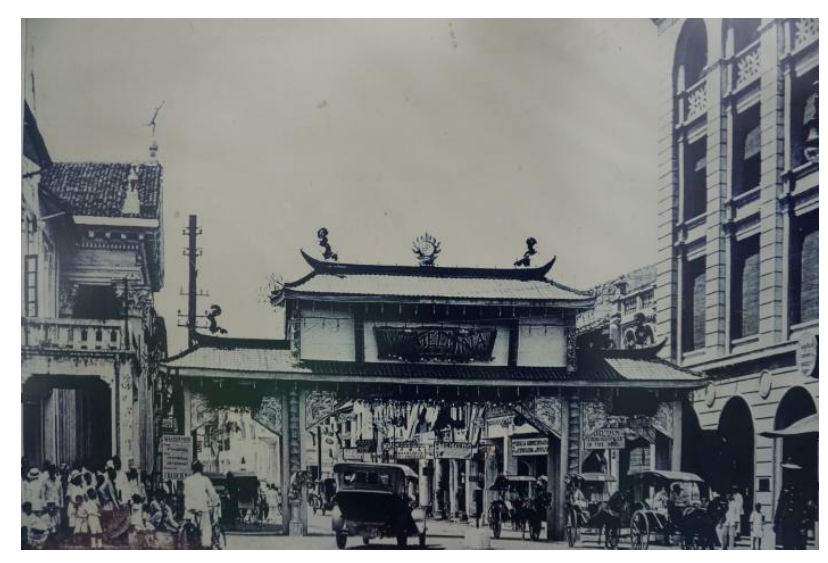

图 1 克萨万地区

\section{3.2 张亚飞故居}

1899 年, 克萨万地区建造了一座大房子。这栋房屋面积为 8000 平方米, 建 筑面积为 6000 平方米, 属于中国人少将张亚飞个人房子, 他兄长张榕轩死后于 1885 年 9 月 4 日被荷兰人加冕为他。这所房子有传统中国、马来和荷兰建筑风 格。这座建筑拥有漂亮的木雕, 并在张亚飞家门的两侧各有两个狮子雕像。 1886 年，他将自己的商业帝国迁至棉兰，这座城市被称为东苏门答腊省的首府。 当时, 棉兰位于德理河和巴布拉河之间的一个小村庄。张亚飞在克萨万地区 （曾经是当地居民的稻田）建造了自己的房子, 然后发展成为一个新的商务中心 （引用资料 Liflet BPCB Aceh，2016 年）。

张亚飞的房屋（图 2) 是建筑中心, 因为它是烟草生产中最高人工林官员的 住所。该建筑曾经是住宅, 自 2010 年以来, 根据部长法令 PM. 01 / PW. 007 / MKP / 2010 号的证明书, 它已被印度尼西亚共和国教育和文化部指定为国家文化 遗产建筑。物理形式并未发生重大变化, 仅更换了受损的瓷砖并定期对房屋建 筑物的墙壁进行了粉刷。 


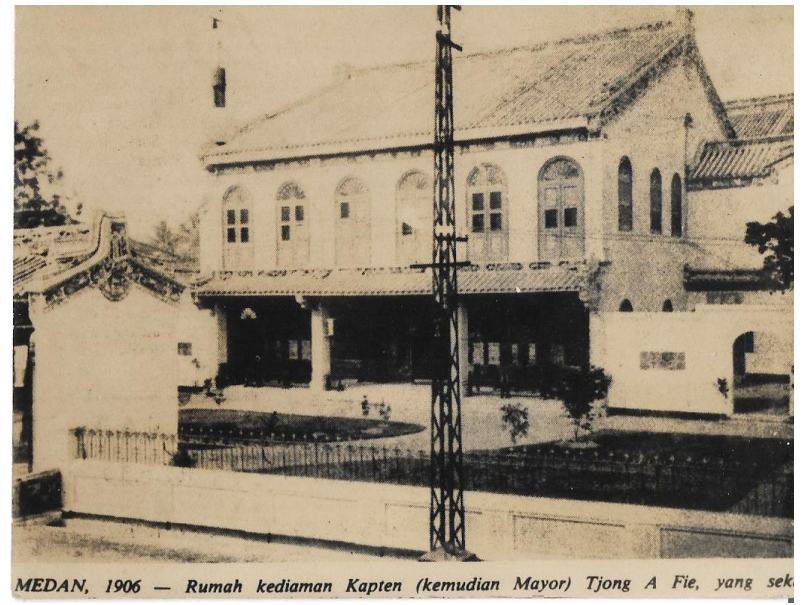

图 2 张亚飞故居

\section{3. 3 Tip Top 餐厅}

一家餐厅的存在是支持欧洲人生活的辅助设施之一, 这与人类的基本需求 (即饮食) 有关。对于居住在殖民地国家的荷兰人, 例如具有热带气候的荷兰 东印群岛与原籍国大不相同, 当然需要进行特殊的调整, 包括饮食方面。另一 方面，对于当时倾向于交易的中国人来说，这可能是一个商机。然后，这个机 会被中国人后裔张杰叶（Jang Kie Yap）利用，他后来开了一家名为 Tip Top 的 餐厅（午餐室）。

Tip Top 餐厅是棉兰市克萨万地区殖民时期烹杄历史杰出的一部分。这家餐 厅的名字叫 Tip Top, 之前名为 Jang Kie, 成立于 1929 年。五年后从 1934 年 这家餐厅搬到了当时的礼宾大道, 商务中心和办公室的克萨万地区。搬家后, 这家餐厅更名为 Tip Top，意为优质或完美。

1942 年日本占领期间, Tip Top 的名称再次更改为 Jang Kie, 因为日本人认 为 Tip Top 是属于荷兰文化。日本殖民时期结束后, 印度尼西亚进入独立时 代, 这家餐厅的名称像今天一样又改回了 Tip Top。 


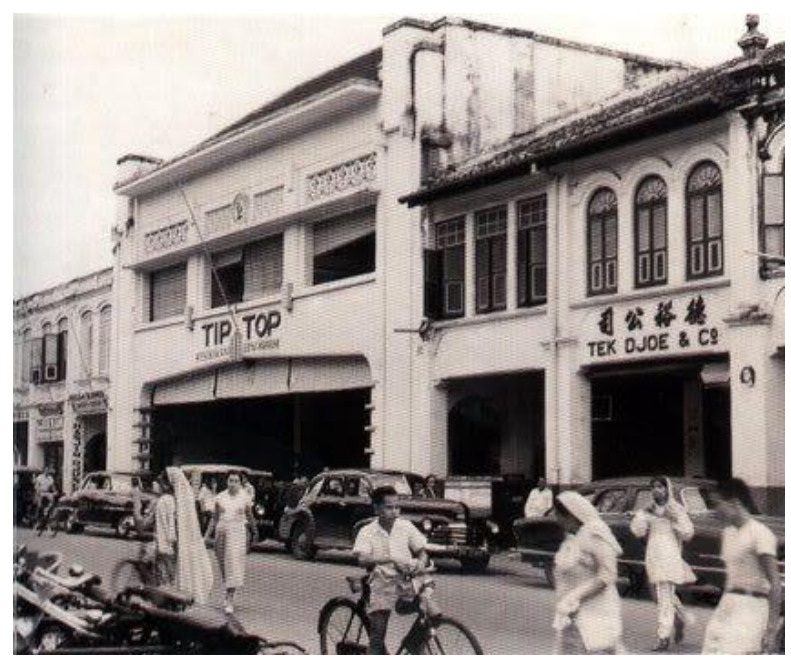

图3 Tip Top餐厅

\subsection{4 阿夫罗斯/ 伦敦苏门答腊大楼}

阿夫罗斯/伦敦苏门答腊大楼是棉兰荷兰殖民主义的文物建筑之一，至今仍 保存完好, 至今仍在使用。最佳的参观时间是在周六和周日, 因为其他几天伦敦 苏门答腊的办公楼充满了办公场所。成为棉兰克萨万地区的旅游圣地之一。位于 城市中心, 就在艾哈迈德 - 亚尼街 (Ahmad Yani) 或称为克萨万街, 伦敦苏门答 腊大楼的建筑物就位于独立广场旁边。参观者只需将车辆引导至 Merdeka Walk 饮食中心，伦敦苏门答腊大楼就位于该中心。伦敦苏门答腊大楼（俗称 Lonsum 大楼）于 1906 年竣工。该大楼由位于伦敦的 Harrison 橡胶种植园和 Crossfield 公司 (H\&C) 的所有者 David Harrison 建造。Lonsum 大楼建有五层楼, 整个建 筑是白色的。Lonsum 大楼的形式类似于 18-19 世纪伦敦的房屋风格。从左窗和 右窗的形状可以看出, 建筑模型受欧洲风格的影响。同时, 长而宽的窗户以及入 口前的大型楼梯可以看到荷兰殖民时期的建筑风格。即使它建于 1906 年代, 这 座建筑的设施也令人印象深刻。

阿夫罗斯/伦敦苏门答腊大楼被列为棉兰市第一座使用跨越五层楼的电梯技 术的大楼。那时 Lonsum 大楼曾是贸易和种植园办公室。印度尼西亚独立后, 哈里森和 Crossfield 公司的所有权就移交给了印度尼西亚政府。目前, 伦敦苏 门答腊大楼仍用作 Lonsum 办公大楼, 并将其更名为 PP 伦敦苏门答腊有限公司。 
由于位于市中心, Lonsum 建筑物经常受到本地或外国游客的称赞, 对它的存在及 遗产特别感兴趣成为观光景点。

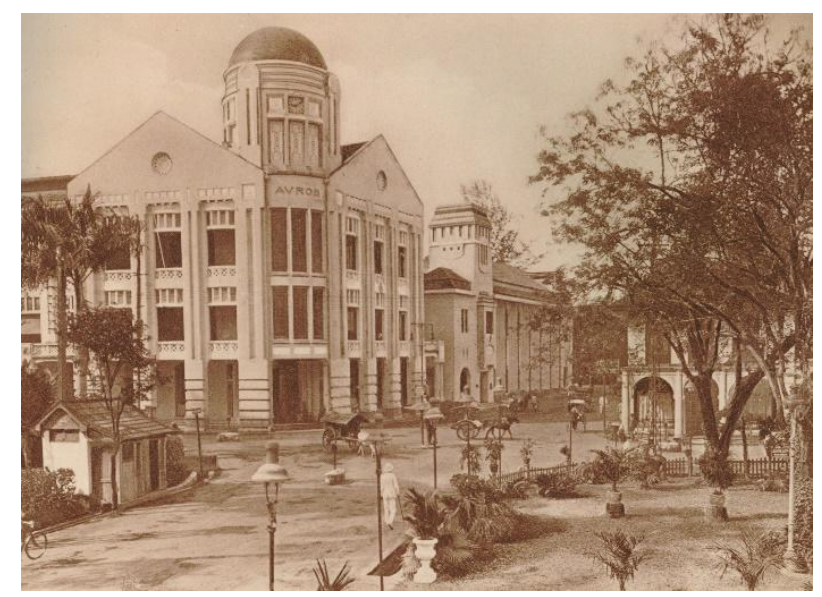

图 4 阿夫罗斯/ 伦敦苏门答腊大楼

\subsection{5 克萨万唐人街建筑形态特征}

形态学是表达物理和空间结构的一种方法, 是形态学和类型学研究的结合。 形态学是形式科学, 是多种科学因素, 会影响定居形式。同时, 建筑类型学是 一个根据基本特征的相似性将一组对象分类的概念（Sulistijowati， 1991 年）。基本特征的相似性基于（1）身份，（2）空间，（3）屋顶形状，墙壁/ 门窗, 地板和 (4) 建筑功能。

基于身份的表型学表现为物理形式, 隔间, 内部空间量以及所用的建筑材 料。从物理上看, 这五座建筑物有一个正方形的平面图。可见的区别是用于建 筑物墙壁和屋顶覆盖材料以及建筑物区域的材料。用墙壁制成的建筑墙壁材 料。灰泥和石头, 仅涂灰泥的墙壁以及灰泥墙壁和竹棚。然后, 没有围栏的房 屋往往会与其他建筑物（房屋和工厂）并排放置。此外，根据整个房屋面积的 不同，内部空间的空间量也有所不同。基于建筑物空间的形态学与住宅空间的 布局, 建筑物的方向和层次结构有关。张亚飞的故居在住宅空间布局中是建筑物 的中心，而其他房屋则位于克萨万地区。

建筑物结构的表型学表明, 建筑物分为三个部分, 即屋顶（建筑物的头 部), 房屋墙壁（建筑物的主体）的开口（门, 窗户, 通风) 以及地板和地基 
（建筑物的支脚）。同时, 基于功能的类型学是一种功能, 从建立之初到现 在, 它一直是房子或住所。有些功能从过去的住所转变为现在的政府机关、商 店、银行、饭店和博物馆。

Andre Loeckx 和 Markus Zahnd 的形态学和形态学理论, 对克萨万聚落区的 形态特征进行了如下绘制。

总体规划: 克萨万移民区似乎规划良好, 土地分为两部分, 即建筑用地和开 放空间。张亚飞故居与克萨万地区的其他住宅并排放置。建筑物的功能往往被 用作房屋和商店。然后, 在艾哈迈德 - 亚尼街的尽头, 以相当大的田野形式出 现一个开放空间。艾哈迈德 - 亚尼街（Ahmad Yani），确是今天的棉兰独立广 场的市中心。

根据外观, 克萨万地区的房屋处于三种状态, 即良好, 中等和不良。张亚飞 故居和阿夫罗斯/伦敦苏门答腊大楼建筑物表现出良好的状态, 对基础, 墙壁和 屋顶均无损坏。中型类别包括 Tip Top 餐厅, 其特征是对屋顶和后壁的轻微损 坏。苏门答腊省文化厅和旅游局大楼中的旧建筑物属于不良建筑物类别中, 这 些建筑物的屋顶和砾石，墙壁，地板和内部空间的一部分已受损。

克萨万地区的房屋外墙看起来宏伟而坚固，顶部是抹灰的墙壁，下面是河 石。门窗的材料和颜色为高度规划建筑提供了信息。然后, 地板覆盖材料作为 主要元素通常使用纯灰色瓷砖。特别是在张亚飞故居的地板上, 它更加多样 化, 即具有六角形图案的褐红色瓷砖, 纯黄色和红色以及水泥地板。同时, 房 屋和其他建筑物上覆盖着带有六角形图案的灰色瓷砖和纯红色瓷砖。

建筑规模：张亚飞故居的建筑面积为 6000 至 8000 平方米。该建筑物的房 间数介于 33 至 35 房间, 内部布局为官方住所。通常由客厅、家庭房、卧室、 厨房、卫生间和多功能厅组成。车库后来被建造为单独的建筑物。

开放空间和树木: 张亚飞的住所有一个开放空间, 其形式为院落, 其中低矮 的植物用于装饰, 高大的树木用于遮阳。高大的树木在院子中间, 院子周围和 建筑物两侧的位置。低矮的植物存放在高大的树木之间、露台的前面、侧面、 在建筑物的每个角落和周围。 
房子院子围绕着建筑物, 或者有前院, 侧面院和后院。院子的形状倾向于 跟随房屋或正方形的形状, 但是也有带有圆形花园的页面形式。故意种植的植物 类型, 院子通常分为两部分, 有一个院子作为花园, 低矮的植物作为装饰（开花 或无花）。还有一个用作果园的院子, 位于房屋旁边或后院。但是, 还有一个 院子, 里面装有观赏植物以及果园或遮荫的木头。

循环系统: 循环系统可以解释为空气循环系统以及建筑物内外通道的循环系 统。空气循环系统处理建筑物主体（墙壁）或建筑物头部（屋顶）中的门窗。 空气通过墙壁上的开口（门, 窗户和通风口）几乎充满了整个墙壁。白天, 空 气流通孔还可以作为室内空间的自然采光（Nuralia，2016 年）。这种情况也节 省电能。空气的顺畅流通和自然采光是一种有效的节能方法。白天几乎不需要 使用风扇和灯光。

良好的道路流通（进出通道）还可以提供舒适和健康的房屋。特别是对于 与其他建筑物分隔开的官邸, 房屋可以通过自己的特殊道路轻松地进出。从道 路的宽度和不止一种出口的存在可以看出道路等级。四轮和两轮车辆可以进 出, 有供行人专用的道路, 用以衡量居住者的社会地位。院子区域的南部和陆 地表面高于主要道路区域。在此部分中, 有两条路径, 即多层楼梯以及宽和圆 形的上行柏油路。

便捷且独立的出入通道显示了种植园结构中的等级制度, 居民占据了上层或 较高的社会地位。与没有特殊宽阔道路的员工相比, 该官员的住房状况有所不 同。极低的频率或密度表示宽敞的空地, 道路仅指定用于一所房屋。这种情况 表明, 该房屋的居住者具有较高的社会地位, 他们来自头等舱 (马来人、欧洲 人、中国人），并担任高级官员。

建筑物功能: 建筑物的功能会影响建筑物的结构, 无论是居住空间中的布 局, 还是其物理形式和建筑物中的布局。指定为高级种植园官员的住宅将作为 住宅的建筑中心, 例如张亚飞故居。然后, 它下面的官邸将位于要塞边缘或单 独站土地上的附属房屋。 
Vol.5, No.2, Oktober 2021: P111-122 E-ISSN: 2579-4906

建筑物的形式就像是垂直的形式结构, 遵循人体的形态。形式结构具有三 个主要部分, 即头部, 身体和脚。头部是屋顶的一部分, 用于保护整个身体 （墙壁）和脚（基础和地板）。建筑物中的布局具有不对称图案。

克萨万地区的房屋似乎采用了特殊的建筑概念, 并且经过精心规划, 因此可 以从外观上看到舒适, 安全, 美观和便利。设计形式的艺术以及装饰和建筑技 术的形式包括设计、建造、装饰和美化的过程（Sumalyo，2003 年），这是建立 高级官邸的主要因素。

高级官员的房屋的建筑风格也参考他们那个时代著名（趋势）的风格。 20 世纪初期在克萨万地区建立住所，当时的建筑风格趋势是印、欧、中式风格。 印、欧、中式不仅取代了 19 世纪的帝国风格。大约在 19 世纪末-10 世纪初, 或 者 1890-1915 年之间, 是指荷兰东印群岛建筑发展的分期阶段（Hartono， 2006 年）。物理形式和预计的成立年份倾向于采用过渡性建筑风格。具有过渡架构的 殖民地房屋优先功能, 因此不再需要精致的圆柱元素和装饰。在这种情况下, 将 根据房屋的需求和功能调整对象的样式和布置。

建筑规划已根据其作为住宅的功能来确定。高级官员的住所是根据其职来安 排和管理的, 旨在供具有较高社会地位的官员使用。然后确定土地将选择谁是位 于特殊土地上的房屋的占用人。根据 Ian Hodder，所有对象都以三种方式工作， 即执行时间分析、功能分析和对象结构分析（Hodder，2013 年）。

\section{4 结论}

根据地貌和地理条件, 克萨万地区的殖民地建筑具有典型的荷兰一中国形 状，包括建筑物的物理形式、布局和功能。建筑物的形状和模型看起来具有欧洲 风格, 并结合了中国文化（繁体中繁体中文）元素, 包括从 19 世纪（印帝国风 格）到 20 世纪（印欧风格）的过渡建筑风格。该建筑物的平面图具有庞大的基 础; 一层的建筑模型; 厚厚的灰泥墙, 天然石材; 大的多个门窗; 大型屋顶, 上 面有瓦和瓦楞铁, 屋顶的形状遵循当地的建筑形式, 如 jolopong 屋顶和 parahu kumereb 屋顶, 或两者兼而有之。典型特征布局和材料中特别明显。该建筑采用 了跟随其时代的建筑, 并且由于建筑的功能（即作为高级种植园官的住所）而看 起来规划得很好。 
建筑物的位置在平坦的土地上, 并且远离道路。住宅位于克萨万地区, 就在 北苏门答腊省棉兰市艾哈迈德 - 亚尼街（Ahmad Yani）。克萨万地区是平坦的土 地，这会影响建筑物的形态。

在荷兰殖民时代, 该建筑作为种植园官员的住所的功能影响了该住宅建筑的 形态特征。因此建筑物的类型、形态、功能和特征之间存在相互作用。此外整体 形态与其居民（即社区）之间存在相互作用。建筑物的物理形式具有意义如在棉 兰市社区结构中也显示出居民的社会地位。 


\section{参考文献}

[1]Buiskool, D. A. 6 The Chinese Commercial Elite of Medan, 1890-1942: The Penang Connection. Journal of the Malaysian Branch of the Royal Asiatic Society,2009, 82(2), 113.

[2]Dewi, A., Antariksa, A., \& Soesanto, S. Pengaruh Kegiatan Berdagang terhadap Pola Ruang-Dalam Bangunan Rumah-Toko di Kawasan Pecinan Kota Malang. DIMENSI (Journal of Architecture and Built Environment), 2005, 33(1).

[3]Harisun, E., \& Conoras, M. A. M. Karakteristik Tipologi Arsitektur Kolonial Belanda Rumah Bastion Benteng Fort Oranje Di Ternate. Journal Of Science And Engineering, 2018, 1(1).

[4]Handinoto, H. Daendels Dan Perkembangan Arsitektur Di Hindia Belanda Abad 19. DIMENSI (Journal of Architecture and Built Environment), 2009, 36(1), pp43.

[5]Handinoto, H., \& Hartono, S. Arsitektur Transisi di Nusantara Dari Akhir Abad 19 ke Awal Abad 20 (Studi Kasus Komplek Bangunan Militer di Jawa pada Peralihan Abad 19 ke 20). DIMENSI (Journal of Architecture and Built Environment),2006, 34(2), 81-92.

[6]Keling, G. Tipologi Bangunan Kolonial Belanda di Singaraja. Jurnal Arkeologi, 2016, 29(2), 65-80.

[7]Lobeck, A. K. Geomorphology: An Introduction to The Study of Landscapes, McGraw-Hill Book Co., New York-London, Chapter III-IV.1939.

[8]Rudiansyah. Tipologi dan Makna Simbolis Rumah Tjong A Fie. Yogyakarta: Estilisium. 2016.

[9]Rudiansyah, Gunardi, G. and Nugrahanto, W. Unsur Akulturasi Budaya pada Rumah Tjong A Fie di Kota Medan. PANTUN, 2019, 2(1).

[10]Salim, P. Arsitektur Cina pada klenteng Jin De Yuan di kawasan Pecinan Jakarta sebagai suatu perwujudan akulturasi kebudayaan. Humaniora, 2012, 3(2), 413421.

[11]Tanjung, R., Rudiansyah, R., \& Chen, J. Lama Gang Bengkok Mosque As A Multiethnic Symbol In The City Of Medan. Jadecs, 2019, 4(2), 95-103. 
[12]Wonoseputro, C. Ruang Publik Sebagai Tempat Bermain Bagi Anak-Anak: Studi Kasus Pengembangan" The Urban Zoo" Bagi Kawasan Pecinan di Singapura. DIMENSI (Journal of Architecture and Built Environment), 2007, 35(1), 73-79.

[13]Wulanningrum, S. D. Identifikasi Kelayakan Kawasan Pecinan Lasem sebagai Kawasan Konservasi. Jurnal Muara Ilmu Sosial, Humaniora, dan Seni, 2017, 1(1), 278-287.

[14]Yusiana, L. S. Konsep Interpretasi Guna Melestarikan Tapak Sejarah di Pecinan Jalan Gajah Mada, Denpasar. Jurnal Arsitektur Lansekap, 2016, 165-176.

Catatan:

Artikel pernah dipresentasikan pada Seminar Nasional APSMI 24 Oktober 2020 